\title{
Mechanism and Kinetics of Solid-State Transformation in High-Temperature Processed Linepipe Steel
}

\author{
P. Yan and H. K. D. H. Bhadeshia \\ University of Cambridge \\ Materials Science and Metallurgy \\ Pembroke Street, Cambridge CB2 3QZ, U.K.
}

\begin{abstract}
A relatively new class of linepipe steels with yield strength above $500 \mathrm{MPa}$ created for thermomechanical processing at temperatures in excess of $1473 \mathrm{~K}\left(1200^{\circ} \mathrm{C}\right)$ has established a firm foothold in the market for modern, large diameter, and high pressure gas transmission systems. The design concept for the steels takes advantage of the enhanced role which higher levels of niobium can play in very low carbon steels, during the plate manufacturing process. The transformation products observed after cooling have been interpreted in conflicting ways in the literature, using ambiguous terms which are not established rigorously. Revealing characterisationexperiments have therefore been conducted to establish that the principal transformation product grows by a displacive transformation mechanism, and that it is properly identified as bainite. The implications of this, both on the interpretation of microstructure and on the processing of the steel, are discussed.
\end{abstract}

\section{Introduction}

Recent years have witnessed the development and practical application of a novel approach to the production of a high strength linepipe steel which can readily meet the mechanical property requirements of the ISO 3183 and API 5L specifications at yield strength levels well in excess of $520 \mathrm{MPa}$, and probably up to at least $620 \mathrm{MPa}$. This potentially covers the microalloyed steel grades from API X75 to X90. The development relies on the application of research performed decades ago [1], with very low carbon steel $(<0.05 \mathrm{wt} \%)$ alloyed with increased levels of niobium. In this compositional regime, niobium plays a role beyond that conventionally associated with microalloying and austenite grain control. Indeed, it is possible with such compositions to thermomechanically process the steel at much higher than normal temperatures, given the ability of niobium to retard the recrystallisation of austenite at elevated temperatures [2-4]. One advantage of this high temperature processing is that mills that are not capable of supporting large rolling forces can be used to produce the steel [2]. 
An immediate stumbling block in establishing structure-property relationships for such steels is that the basis for describing their microstructures is rather weak. There are two approaches that can be adopted: a quantitative description in terms of stereological parameters such as size, shape, uniformity etc., and the second involves classification by naming the constituents, an approach often used in microstructural atlases [5]. The quantitative approach is useful in establishing the structure-property relationships but is infrequently used because it requires considerable effort.

The idea of simply naming complex microstructures which have evolved during continuous cooling transformation is unsatisfactory because it fails to do anything other than establish a subjective means of communication. For example, the most frequently encountered terminology in describing the microstructure of linepipe steel is "acicular ferrite", which was defined after Smith et al. [6] as "a highly substructured, non-equiaxed ferrite that forms on continuous cooling by a mixed diffusion and shear mode of transformation that begins at a temperature slightly higher than the upper bainite transformation range". Examples of similar statements can be found in later publications [7, 8]. It is not clear what such statements actually mean since they are not usually backed by evidence. The term acicular ferrite in the context of weld metals has an entirely different meaning, where it represents plates of ferrite nucleated intragranularly within the austenite on nonmetallic inclusions $[9,10]$, thereafter growing by the same atomic mechanism as the bainite transformation $[11,12]$.

Both of the methods have the disadvantage that they do not add directly to a proper understanding of microstructural evolution that can be exploited in alloy design or in predicting what should happen, either if different processing routes are applied, or if gradients of heat-affected zone structure should be expected following welding operations. Indeed, it may be wrong to refer to the linepipe structure by a single description such as acicular ferrite since the real case may involve the existence of a variety of phases evolving at different temperatures as the steel cools. The fundamental question is whether a new microstructural description is required, or can well-established phases such as bainite, pearlite etc. account for all that is observed in the higher niobium linepipe alloy?

It is very difficult to decipher the atomic mechanisms of transformations in general; the amount of work necessary is illustrated by the accumulated knowledge listed in Table 1, knowledge which has taken many decades to gel into a systematic set [13]. The purpose of the present work was to undertake a detailed study of the transformation mechanisms in the high-Nb X80 steel with a view to similarly establishing the nature of the transformation products. Naturally, not all the aspects listed in Table 1 can be investigated in the short term, but the aim was to identify sufficient characteristics to help distinguish transformation products.

Table 1 illustrates the phenomena which were intended to be studied in the present work for the steel of interest, as listed in the top half. Some sequential discussion of the criteria listed in the top part is relevant here in order to set the experiments that follow in context, although much more detail can be found in [13]. The structure is thermodynamically of first order (nucleation and growth) if the parent and product phases can be simultaneously observed. The actual shape must be characterised in partially transformed samples in order to avoid changes in morphology due to impingement between crystals originating from different regions. The invariant-plane strain (IPS) shape deformation can be characterised using changes in surface topology following transformation. The detection of such a shape deformation would then imply a lattice correspondence between the parent and product phases, a glissile transformation interface, an orientation with the Bain region, 
a high interfacial mobility at low temperatures and an iron to substitutional solute ratio that is preserved during growth. The dislocation density, whether it is consistent with a reconstructive or displacive mechanism, follows from transmission microscope observations.

Table 1: Key transformation characteristics in steels. Martensite $\alpha^{\prime}$, lower bainite $\alpha_{l b}$, upper bainite $\alpha_{u b}$, acicular ferrite $\alpha_{a}$, Widmanstätten ferrite $\alpha_{w}$, allotriomorphic ferrite $\alpha$, idiomorphic ferrite $\alpha_{i}$, pearlite $P$, substitutional solutes $X$. Consistency of a comment with the transformation concerned is indicated by $=$, inconsistency by $\neq$; a bullet $\bullet$ identifies the case where the comment is only sometimes consistent with the transformation. The term parent $\gamma$ implies the $\gamma$ grain from which the product phase grows. Adapted from [14].

Comment
Nucleation and growth reaction
Plate shape
IPS shape change with large shear
Lattice correspondence during growth
Co-operative growth of ferrite and cementite
High dislocation density
Necessarily has a glissile interface
Always has an orientation within the Bain region
Grows across austenite grain boundaries
High interface mobility at low temperatures
Reconstructive diffusion during growth
Bulk redistribution of X atoms during growth
Displacive transformation mechanism
Reconstructive transformation mechanism
Diffusionless nucleation
Only carbon diffuses during nucleation
Reconstructive diffusion during nucleation
Often nucleates intragranularly on defects
Diffusionless growth
Local equilibrium at interface during growth
Local paraequilibrium at interface during growth
Diffusion of carbon during transformation
Carbon diffusion-controlled growth
Incomplete reaction phenomenon

\begin{tabular}{|c|c|c|c|c|c|c|}
\hline$\alpha^{\prime}$ & $\alpha_{l b}$ & $\alpha_{u b}$ & $\alpha_{a}$ & $\alpha_{w}$ & $\alpha$ & $\alpha_{i}$ \\
\hline$=$ & $=$ & $=$ & $=$ & $=$ & $=$ & $=$ \\
\hline$=$ & $=$ & $=$ & $=$ & $=$ & $\neq$ & $\neq$ \\
\hline & $=$ & $=$ & $=$ & $=$ & $\neq$ & $\neq$ \\
\hline$=$ & $=$ & $=$ & $=$ & $\neq$ & $\neq$ & $\neq$ \\
\hline$\neq$ & $\neq$ & $\neq$ & $\neq$ & $\neq$ & $\neq$ & $\neq$ \\
\hline$=$ & $=$ & $=$ & $=$ & • & $\neq$ & $\neq$ \\
\hline$=$ & $=$ & $=$ & $=$ & $=$ & $\neq$ & $\neq$ \\
\hline$=$ & $=$ & $=$ & $=$ & $=$ & $\neq$ & $\neq$ \\
\hline$\neq$ & $\neq$ & $\neq$ & $\neq$ & $\neq$ & $=$ & $=$ \\
\hline$=$ & $=$ & $=$ & $=$ & $=$ & $\neq$ & $\neq$ \\
\hline$\neq$ & $\neq$ & $\neq$ & $\neq$ & $\neq$ & $=$ & $=$ \\
\hline$\neq$ & $\neq$ & $\neq$ & $\neq$ & $\neq$ & • & $\bullet$ \\
\hline$=$ & $=$ & $=$ & $=$ & $=$ & $\neq$ & $\neq$ \\
\hline$\neq$ & $\neq$ & $\neq$ & $\neq$ & $\neq$ & $=$ & $=$ \\
\hline$=$ & $\neq$ & $\neq$ & $\neq$ & $\neq$ & $\neq$ & $\neq$ \\
\hline$\neq$ & $=$ & $=$ & $=$ & $=$ & $\neq$ & $\neq$ \\
\hline$\neq$ & $\neq$ & $\neq$ & $\neq$ & $\neq$ & $=$ & $=$ \\
\hline$=$ & $\neq$ & $\neq$ & $=$ & $\neq$ & $\neq$ & $=$ \\
\hline$=$ & $=$ & $=$ & $=$ & $\neq$ & $\neq$ & $\neq$ \\
\hline$\neq$ & $\neq$ & $\neq$ & $\neq$ & $\neq$ & • & - \\
\hline$\neq$ & $\neq$ & $\neq$ & $\neq$ & $=$ & • & $\bullet$ \\
\hline$\neq$ & $\neq$ & $\neq$ & $\neq$ & $=$ & $=$ & $=$ \\
\hline$\neq$ & $\neq$ & $\neq$ & $\neq$ & $=$ & • & $\bullet$ \\
\hline$\neq$ & $=$ & $=$ & $=$ & $\neq$ & $\neq$ & $\neq$ \\
\hline
\end{tabular}

\section{Experimental Procedures}

The pipe steel studied, which has a chemical composition listed in Table 2, derives from a significant pioneering X80 project.

Heat treatments were performed using a THERMECMASTER thermomechanical simulator using cylindrical samples of diameter $8 \mathrm{~mm}$ height of $12 \mathrm{~mm}$ along the normal to the steel plate. Isothermal heat treatments were conducted by austenitising the specimens at $1533 \mathrm{~K}\left(1260^{\circ} \mathrm{C}\right)$ for $1 \mathrm{~min}$, quenching to different temperatures and holding for periods up to $1 \mathrm{~h}$ before gas-quenching to room 
Table 2: Chemical composition, wt\%

\begin{tabular}{ccccccc}
\hline $\mathrm{C}$ & $\mathrm{Mn}$ & $\mathrm{P}$ & $\mathrm{S}$ & $\mathrm{Si}$ & $\mathrm{Cu}$ & $\mathrm{Ni}$ \\
0.05 & 1.55 & 0.012 & 0.002 & 0.12 & 0.24 & 0.13 \\
$\mathrm{Nb}$ & $\mathrm{Al}$ & $\mathrm{Cr}$ & $\mathrm{Ti}$ & $\mathrm{N}$ & $\mathrm{Ca}$ & \\
0.095 & 0.037 & 0.23 & 0.011 & 0.0033 & 0.0012 & \\
\hline
\end{tabular}

temperature at $20 \mathrm{~K} \mathrm{~s}^{-1}$. Note that the austenitisation temperature corresponds to that utilised during plate processing.

Metallographic samples were ground using sand paper, polished with diamond paste and then etched with $3 \%$ nital, followed by characterisation using a Zeiss Axiotech optical and a JEOL 5800LV scanning electron microscope. Microhardness measurements were carried out on the etched surfaces using a Mitutoyo microhardness tester with a load of $100 \mathrm{gf}$ and dwell time of $10 \mathrm{~s}$. Transmission electron microscopy (JOEL 200CX microscope) utilised thin films prepared by electropolishing with a solution of $15 \%$ perchloric acid and $85 \%$ ethanol at $20 \mathrm{~V}$ and $273 \mathrm{~K}\left(0^{\circ} \mathrm{C}\right)$.

Surface displacements caused by the coordinated motion of atoms were studied by polishing samples to a $1 \mu \mathrm{m}$ finish, followed by cleaning with ethanol during ultrasonic agitation. The sample was then austenitised at $1533 \mathrm{~K}\left(1260^{\circ} \mathrm{C}\right)$ for $1 \mathrm{~min}$, and cooled continuously to ambient temperature at $\sim 10 \mathrm{~K} \mathrm{~s}^{-1}$ in the thermomechanical simulator under vacuum. The resulting surface displacements were characterised using a Veeco Dimension 3100 atomic force microscope in tapping mode, with images acquired at $512 \times 512$ pixel resolution at a scan rate of $1 \mathrm{~Hz}$.

\section{Results and Discussion}

The time-temperature-transformation (TTT) diagram of the X80 steel, shown in Fig. 1a, was constructed by isothermal transformations for $1 \mathrm{~h}$ at the temperature range from 823 (550) to $1023 \mathrm{~K}\left(750^{\circ} \mathrm{C}\right)$. The C-curves represent absolute volume fraction (vol\%) of the transformations using the offset method [15] on the isothermal transformation dilatometry curves. Maximum volume changes from complete transformations at various holding temperatures were measured by the gradients of the austenite and ferrite segments on the continuous cooling curve. The measured TTT diagram shows good match with the calculation using MUCG algorithm [16] except the delaying of allotriomorphic ferrite transformation, because the program does not consider the effect of $\mathrm{Nb}$ micro-alloying on hardenability, details of which are discussed elsewhere [17].

At $1023 \mathrm{~K}\left(750^{\circ} \mathrm{C}\right)$ no transformation took place during the $1 \mathrm{~h}$ holding time. The slight expansion shown in Fig. 2a is possibly from thermal or measurement fluctuations. The sample remained fully austenitic, and transformation occurred subsequent to quenching at $839 \mathrm{~K}\left(566^{\circ} \mathrm{C}\right)$ (Fig. $\left.2 \mathrm{~b}\right)$. It is similar to the transformation-start temperature of the sample continuously cooled at the same rate without isothermal holding. This confirms that no transformation occurs during the holding at 
$1023 \mathrm{~K}\left(750^{\circ} \mathrm{C}\right)$, otherwise the transformation-start temperature during cooling would decrease due to the carbon enrichment in the remaining austenite. The resultant microstructure is a mixture of bainite, $\alpha_{b}$ and martensite, $\alpha^{\prime}$, examples of which are annotated in Fig. 3.

At $973(700)$ and $923 \mathrm{~K}\left(650^{\circ} \mathrm{C}\right)$, the steel transformed into allotriomorphic ferrite during the $1 \mathrm{~h}$ holding period with the consequence that the residual austenite becomes enriched in carbon, to subsequently transform into martensite on quenching, Figs. 3b and c. This is consistent with the dilatometric data, Fig. 2. The hardness of the martensite in the sample transformed isothermally at $923 \mathrm{~K}\left(650^{\circ} \mathrm{C}\right)$ is $565 \pm 66 \mathrm{HV}$, which is much harder than that in the sample similarly transformed at $973 \mathrm{~K}\left(700^{\circ} \mathrm{C}\right)$, which is $388 \pm 59 \mathrm{HV}$. This is because more ferrite forms at $923 \mathrm{~K}\left(650^{\circ} \mathrm{C}\right)$, thus causing a greater enrichment of the smaller quantity of residual austenite, so that harder martensite is produced on quenching. The hardness of the ferrite was similar in both samples at $183 \pm 17 \mathrm{HV}$.

The transformation in the range $773-923 \mathrm{~K}\left(500-650^{\circ} \mathrm{C}\right)$ is identified with bainite (Fig. 1), as will be confirmed by the experiments reported later in the paper. 87 and $90 \mathrm{vol} \%$ of the materials transformed after holding $1 \mathrm{~h}$ at $873(600)$ and $823 \mathrm{~K}\left(550^{\circ} \mathrm{C}\right)$, respectively, measured by the isothermal dilatometry curves, which match the amount of bainite formed when the carbon content of the remaining austenite reaches $T_{0}$ calculated using MUCG algorithm [16]. The beginning of the transformation was rapid, almost coinciding with the point where the isothermal temperatures were reached, as shown in Fig. 4a. The plate-like structure, which is characteristic of bainite, is more prominent in the sample isothermally transformed at the lower temperature of $823 \mathrm{~K}\left(550^{\circ} \mathrm{C}\right)$. It is similar to the bainite region in the sample quenched from $1023 \mathrm{~K}\left(750^{\circ} \mathrm{C}\right)(c f$. Fig. $4 \mathrm{c}$ and $3 \mathrm{a})$. The martensite-start temperature $\left(M_{S}\right)$ is $738 \mathrm{~K}\left(465^{\circ} \mathrm{C}\right)$ calculated using MUCG program [16]. It turned out to be impossible for the available equipment to cool the sample down fast enough to prevent the transformation from taking place as the holding temperature approached the $M_{S}$, so isothermal heat treatment at lower temperatures than $823 \mathrm{~K}\left(550^{\circ} \mathrm{C}\right)$ was not performed. During quenching from $1023 \mathrm{~K}\left(750^{\circ} \mathrm{C}\right)$, the steel transformed in the temperature range between $839(566)$ and $708 \mathrm{~K}\left(435^{\circ} \mathrm{C}\right)$ (Fig. 2b), leading to a mixture of bainite and martensite structure, which is consistent with the TTT diagram.

A clear plate-like structure was also obtained by isothermal transformation at $873 \mathrm{~K}\left(600^{\circ} \mathrm{C}\right)$ for only $30 \mathrm{~s}$ as shown in Fig. 5, which represents the early stage of the bainite transformation. The martensite due to the decomposition of the residual austenite upon cooling is revealed in Fig. 5c. Transmission electron microscopy confirmed the thin-plate morphology of the bainitic ferrite plates with even thinner austenite films in between, Fig. 6 . The presence of austenite was established by electron diffraction and dark field imaging, and the observations showed that the structure that forms is free from cementite precipitates in the early stages of transformation. This is expected from the mechanism of transformation which involves the partitioning of carbon from supersaturated ferrite, with cementite precipitation being a secondary stage [18].

The microstructure illustrated in Fig. 6 is properly described as carbide-free bainite, as frequently observed in silicon- or aluminium- rich steels [19]. Solutes like silicon, which have negligible solubility in cementite [20,21], retard its formation as described elsewhere [22], thus leaving a structure with just bainitic ferrite and carbon-enriched retained austenite. However, the concentration of silicon required in such steels is of the order of $1 \mathrm{wt} \%$ or more, whereas the present alloy contains very little silicon, so it is expected that the precipitation of cementite should occur with prolonged 
holding at the isothermal transformation temperature. Consistent with this, an increase in the isothermal holding time to $1 \mathrm{~h}$ resulted in the expected changes as illustrated in Fig. 7, with the austenite films decomposing to allow some of the bainitic ferrite plates to merge, with the vestiges of the original boundaries identified by the minute particles of cementite highlighted in the darkfield image. It is important to note that the carbide particles are incredibly small because the total carbon concentration of the alloy is only $0.05 \mathrm{wt} \%$. Otherwise, the formation of coarse cementite particles due to the decomposition of the austenite is known to be detrimental to toughness as in classical upper bainite in higher carbon steels [23].

The displacements caused due to the transformation strains associated with the growth of bainitic ferrite were measured using atomic force microscopy, since optical interference techniques do not have the resolution necessary to characterise individual platelets, as opposed to sheaves of bainite plates. The cleaned and polished sample was austenitised in the thermomechanical simulator in a vacuum environment. The dilatometric curve of the heat treatment is shown in Fig. 8 . The transformation happened between $773(500)$ and $873 \mathrm{~K}\left(600^{\circ} \mathrm{C}\right)$ which is in the bainite transformation region of the TTT diagram (Fig. 1). Continuous cooling is essentially involved in industrial thermomechanical processing of the linepipe steel. Although deformation was not applied in this study, the temperature region for bainite transformation in the X80 HTP steel is consistent with the results obtained from deformed steel sample with similar composition [2, 24-26].

The tip of the atomic force microscope was set to scan in a direction approximately perpendicular to the length of the bainite plates as shown in Fig. 9a. Figure 9b shows the three-dimensional representation of the area scanned. The line scan, Fig. 9c, shows that the relief caused by transformation involves a shear (invariant-plane strain) associated with the bainitic ferrite and some plastic relaxation of the adjacent austenite, as has been observed previously [27, 28]. The basic theory has been described elsewhere [27, 28], but since the orientation of the habit plane relative to the free surface is not determined, a shear must be labelled as an apparent shear component $s_{a}$. The true shear $s$ is only measured when the plate is normal to the free surface, so $s \geq s_{a}$. The measured values of $s_{a}$ are summarised in Table 3 . The largest observed value of $s_{a}$ will be closest to the true value $s$, so it can be concluded that $s \geq 0.24$, which is a result close to values reported from earlier research on bainite [27, 29]. There are two conclusions to be drawn from these observations. First, the microstructure obtained is legitimately defined as displacive, leading to shape deformation which determines the plate shape of the bainite, and second, that there can be no partitioning of substitutional solutes during the formation of the microstructure so that the role of alloying elements of this kind is simply to influence the thermodynamic stability of the austenite.

Table 3: Measured values of apparent shear component $s_{a}$ of shape deformation due to the growth of bainite platelets.

\begin{tabular}{cccc}
\hline Sample & Measured $s_{a}$ & Sample & Measured $s_{a}$ \\
\hline 1 & 0.18 & 4 & 0.24 \\
2 & 0.19 & 5 & 0.24 \\
3 & 0.24 & 6 & 0.17 \\
\hline
\end{tabular}


It is not reasonable to describe the microstructure of the X80 steel studied here as 'acicular ferrite', which transforms in the temperature range between $773(500)$ and $923 \mathrm{~K}\left(650^{\circ} \mathrm{C}\right)$, because the transformation product is not acicular, nor is its nucleation stimulated on non-metallic inclusions which cause the overall morphology to change from parallel platelets to plates originating in a star formation from point sites.

\section{Conclusions}

A series of experiments lead to the conclusion that the microstructure of a low-carbon, high-niobium X80 linepipe steel consists of bainite. The phase forms over a temperature range $773-923 \mathrm{~K}$ (500$650^{\circ} \mathrm{C}$ ), initially in the form of thin plates which are separated by fine films of carbon-enriched retained austenite, although the latter then decomposes, leading to the coalescence of adjacent bainitic ferrite platelets and the precipitation of incredibly small cementite particles at the original location of the austenite.

The growth of the bainite platelets causes an invariant-plane strain shape deformation which has a shear component of at least 0.24. This means that the transformation morphology is strain energy dominated and this is the reason why the bainite forms as thin plates, only about $0.2 \mu \mathrm{m}$ in thickness. Furthermore, since the bainite forms at temperatures where the austenite is likely to have a yield strength less than $140 \mathrm{MPa}$ [30], the shape deformation due to bainite formation can not be elastically accommodated, and hence causes plastic relaxation of the adjacent austenite. This in turn is a major microstructural refinement mechanism since the debris created by the plasticity of the austenite limits the length of the bainite plates [31].

Given that the mechanism of transformation has been revealed over the critical range of transformation temperatures, it becomes possible to interpret the development of microstructure during continuous cooling if the transformation temperatures can be monitored either directly or via recalescence effects in cooling curves.

Acknowledgements The authors are grateful to CBMM for financial support and for providing the steel, and would like to thank Dr Philip Kirkwood and Dr Malcolm Gray for helpful discussions. They also thank Professor A. L. Greer for the provision of laboratory facilities at the University of Cambridge.

\section{References}

[1] J. M. Gray, W. W. Wilkening, and L. G. Russell. Transformation characteristics of very-lowcarbon steels. Technical report, U. S. Steel, USA, 1969.

[2] K. Hulka and J. M. Gray. High-temperature processing of line-pipe steels. In Niobium 2001, pages 587-612, Warrendale, Pennsylvania, USA, 2001. TMS-AIME.

[3] D. Stalheim. The use of high temperature processing (HTP) for high strength oil and gas transmission pipeline applications. In Proceedings of the 5th HSLA Steels Conference, Iron and Steel Supplement, volume 40, pages 699-704, 2005. 
[4] Z. X. Qiao, Y. C. Liu, L. M. Yu, and Z. M. Gao. Incompleted bainitic transformation characteristics in an isochronally annealed $30 \mathrm{CrNi} 3 \mathrm{MoV}$ steel. Journal of Alloys and Compounds, 474:334-340, 2009.

[5] T. Araki, editor. Atlas for Bainitic Mcirostructure, volume 1. The Iron and Steel Institute of Japan, Tokyo, Japan, 1992.

[6] Y. E. Smith, A. P. Coldren, and R. L. Cryderman. Manganese-molybdenum-niobium acicular ferrite steels with high strength. In Towards Improved Ductility and Toughness, pages 119-142, Michigan, USA, 1971. Climax Molybdenum Co.

[7] M.-C. Zhao, Y.-Y. Shan, F. R. Xiao, K. Yang, and Y. H. Li. Investigation on the H2S-resistant behaviors of acicular ferrite and ultrafine ferrite. Materials Letters, 57:141-145, 2002.

[8] M. C. Zhao, K. Yang, and Y. Y. Shan. Comparison on strength and toughness behaviors of microalloyed pipeline steels with acicular ferrite and ultrafine ferrite. Materials Letters, 57:1496-1500, 2003.

[9] Y. Ito and M. Nakanishi. Study on charpy impact properties of weld metal with SAW. The Sumitomo Search, 15:42-62, 1976.

[10] D. J. Abson. Nonmetallic inclusions in ferritic steel welds - a review. Technical Report IIW Doc. IX-1486-87, International Institute of Welding, Villepinte, France, 1987.

[11] H. K. D. H. Bhadeshia. Models of acicular ferrite. In S. A. David and J. M. Vitek, editors, International Trends in Welding Research, pages 213-222, Ohio, U. S. A., 1992. ASM International.

[12] S. S. Babu and H. K. D. H. Bhadeshia. Stress and the acicular ferrite transformations. Materials Science and Engineering A, A156:1-9, 1992.

[13] H. K. D. H. Bhadeshia. Rationalisation of shear transformations in steels. Acta Metallurgica, 29:1117-1130, 1981.

[14] H. K. D. H. Bhadeshia. Bainite in Steels, 1st edition. Institute of Materials, London, U.K., 1992.

[15] H.-S. Yang and H. K. D. H. Bhadeshia. Uncertainties in the dilatometric determination of the martensite-start temperature. Materials Science and Technology, 23:556-560, 2007.

[16] H. K. D. H. Bhadeshia. Software for transformations in steels. http://www.msm.cam.ac.uk/map/steel/programs/mucg46-b.html, 1982.

[17] P. Yan et al. Effect of soluble niobium on austenite-ferrite transformation. Prepared for submission, 2013.

[18] M. Takahashi and H. K. D. H. Bhadeshia. Model for transition from upper to lower bainite. Materials Science and Technology, 6:592-603, 1990.

[19] H. K. D. H. Bhadeshia. Bainite in Steels, 2nd edition. Institute of Materials, London, U.K., 2001. 
[20] G. Miyamoto, J. C. Oh, K. Hono, T. Furuhara, and T. Maki. Effect of partitioning of Mn and $\mathrm{Si}$ on the growth kinetics of cementite in tempered $\mathrm{Fe}-0.6$ mass\% C martensite. Acta Materialia, 55:5027-5038, 2007.

[21] J. H. Jang, I. G. Kim, and H. K. D. H. Bhadeshia. Substitutional solution of silicon in cementite: a first-principles study. Computational Materials Science, 44:1319-1326, 2009.

[22] E. Kozeschnik and H. K. D. H. Bhadeshia. Influence of silicon on cementite precipitation in steels. Materials Science and Technology, 24:343-347, 2008.

[23] H. K. D. H. Bhadeshia and D. V. Edmonds. Bainite in silicon steels: a new composition property approach i. Metal Science, 17:411-419, 1983.

[24] P. Cizek. Transformation behaviour and microstructure of an API X80 linepipe steel subjected to simulated thermomechanical processing. In 10th International Metallurgical and Materials Conference METAL 2001, pages Paper 94, 1-8, Ostrava, Czech Republic, 2001. Tanger Ltd.

[25] E. V. Pereloma, C. Bayley, and J. D. Boyd. Microstructural evolution during simulated OLAC processing of a low-carbon microalloyed steel. Materials Science E Engineering A, 210:16-24, 1996.

[26] X. Zeng, J. Lu, and W. Wang. Effect of cooling rate of hot-deformed austenite on structure and property of X80 pipeline steel. Special Steel, 31:63-665, 2010.

[27] E. Swallow and H. K. D. H. Bhadeshia. High resolution observations of displacements caused by bainitic transformation. Materials Science and Technology, 12:121-125, 1996.

[28] M. Peet and H. K. D. H. Bhadeshia. Surface relief due to bainite transformation at 473 K. Metallurgical $\&$ Materials Transactions A, 42:3344-3348, 2011.

[29] B. P. J. Sandvik and H. P. Nevalainen. Structure-property relationships in commercial lowalloy bainitic-austenitic steel with high strength, ductility, and toughness. Metals Technology, 8:213-220, 1981.

[30] P. H. Shipway and H. K. D. H. Bhadeshia. Mechanical stabilisation of bainite. Materials Science \& Engineering A, 11:1116-1128, 1995.

[31] H. K. D. H. Bhadeshia and D. V. Edmonds. The mechanism of bainite formation in steels. Acta Metallurgica, 28:1265-1273, 1980. 


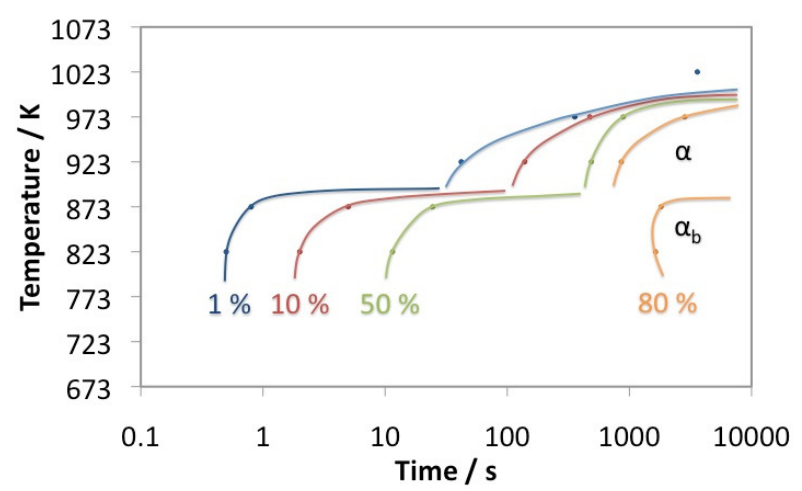

(a) Measured by isothermal transformation. Ccurves represent absolute vol\% of transformation.

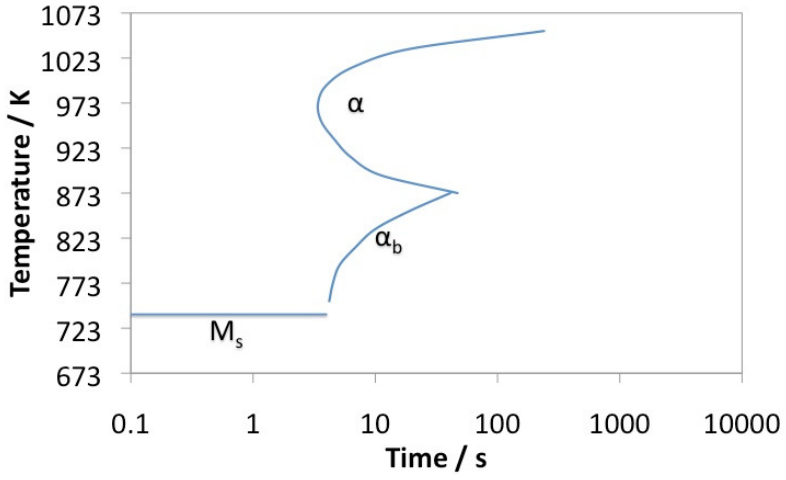

(b) Calculated C-curves representing the initiation of transformation.

Figure 1: TTT diagram of the X80 steel after austenitisation at $1533 \mathrm{~K}\left(1260^{\circ} \mathrm{C}\right)$ for $1 \mathrm{~min}$.

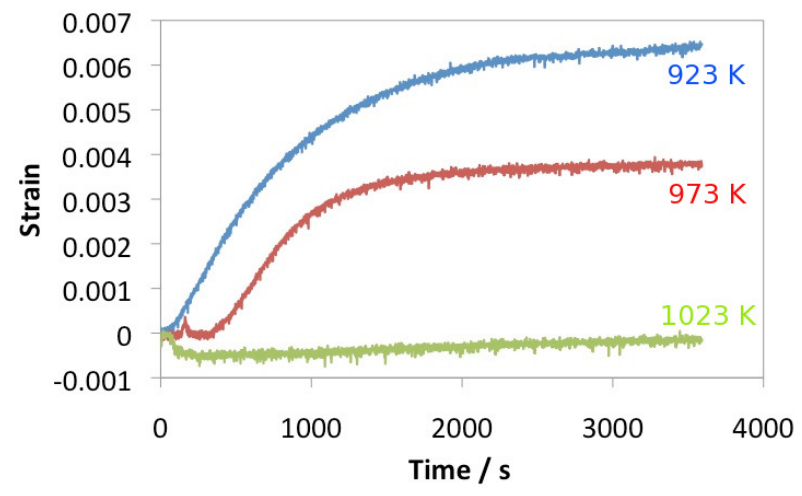

(a) Isothermal holding.

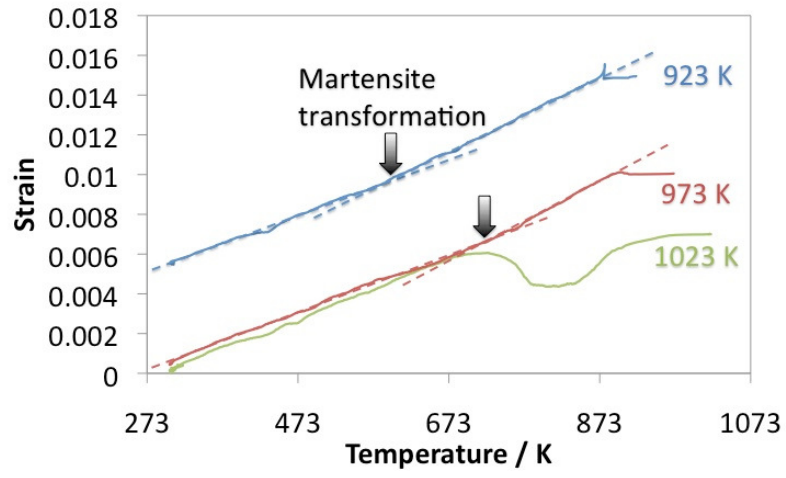

(b) During quenching.

Figure 2: Dilatometric curves of the samples which have been isothermally held at 1023 (750), 973 (700) and $923 \mathrm{~K}\left(650^{\circ} \mathrm{C}\right)$ for $1 \mathrm{~h}$ and quenched to room temperature. 
(a)

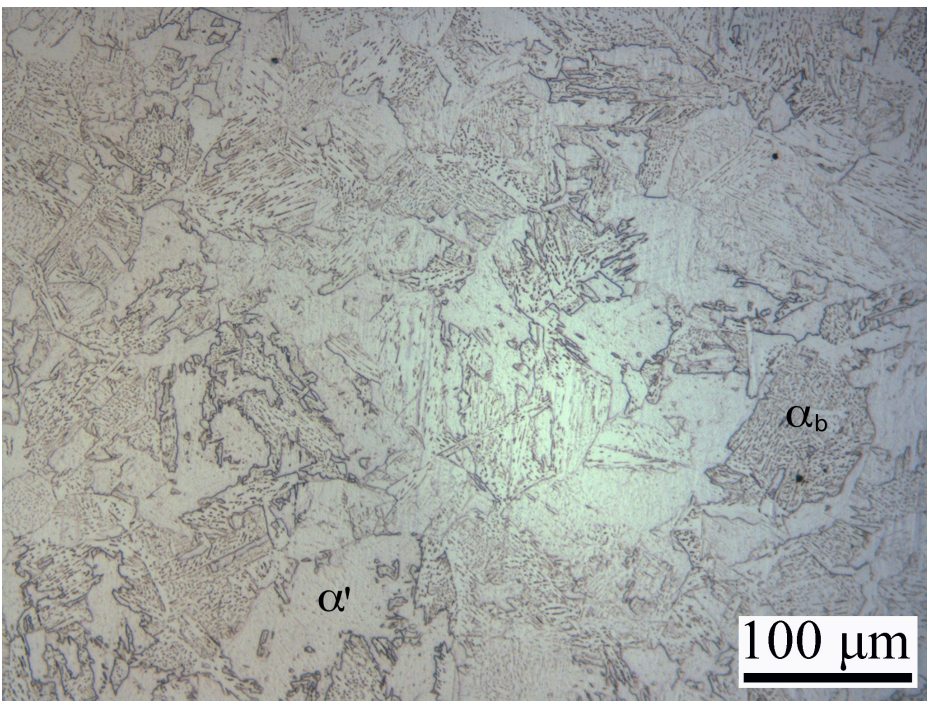

(b)

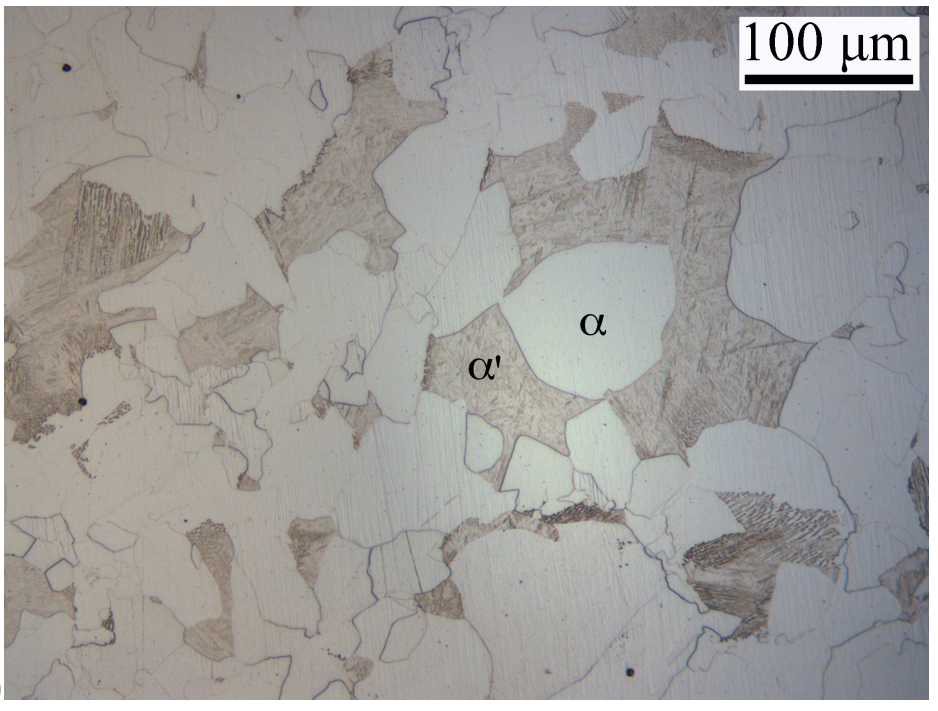

(c)

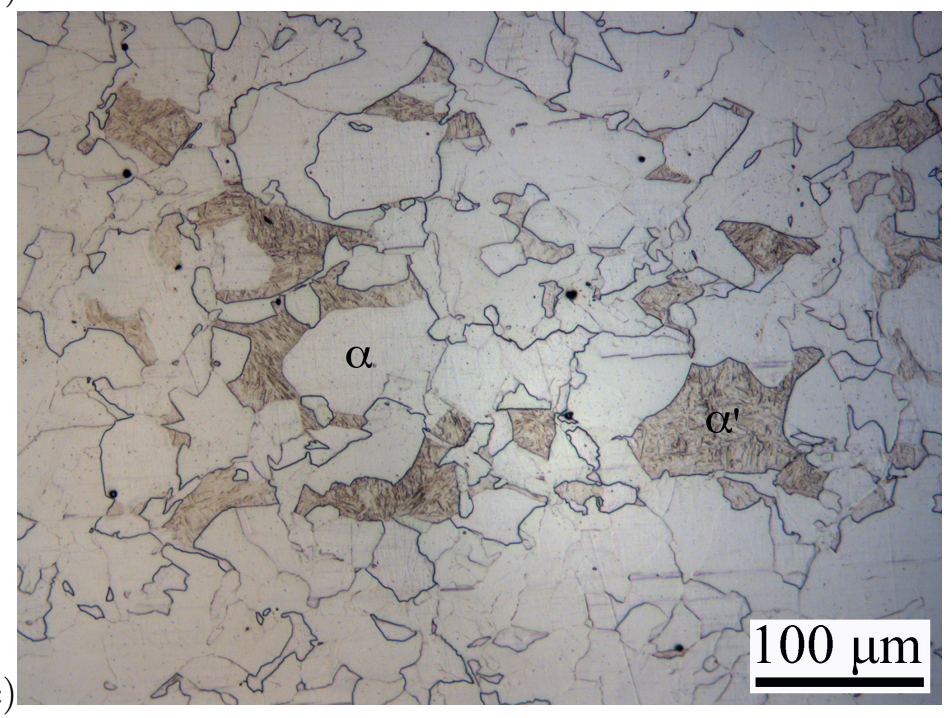

Figure 3: Optical micrographs following isothermal transformation at a variety of temperatures for $1 \mathrm{~h}$ followed by quenching to room temperature: (a) $1023 \mathrm{~K}\left(750^{\circ} \mathrm{C}\right)$, (b) $973 \mathrm{~K}\left(700^{\circ} \mathrm{C}\right)$ and (c) $923 \mathrm{~K}\left(650^{\circ} \mathrm{C}\right) . \alpha$ and $\alpha^{\prime}$ represent allotriomorphic ferrite and martensite respectively, as described in Table 1. 

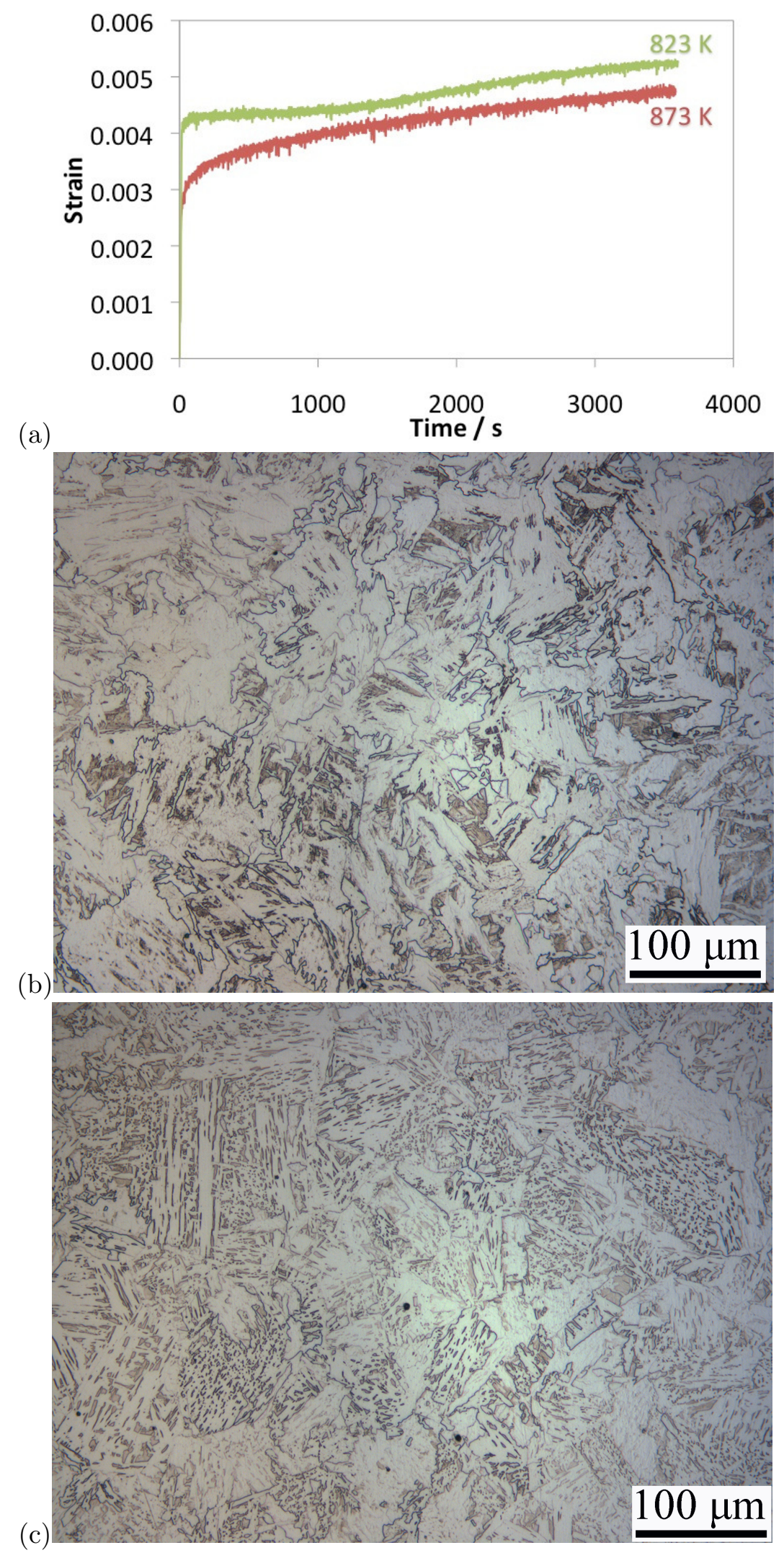

Figure 4: Isothermal heat treatments at $873(600)$ and $823 \mathrm{~K}\left(550^{\circ} \mathrm{C}\right)$ for $1 \mathrm{~h}$ : (a) dilatometry curves, and optical micrographs of samples which have been isothermally held at (b) $873 \mathrm{~K}\left(600^{\circ} \mathrm{C}\right)$ and (c) $823 \mathrm{~K}\left(550^{\circ} \mathrm{C}\right)$ for $1 \mathrm{~h}$. 


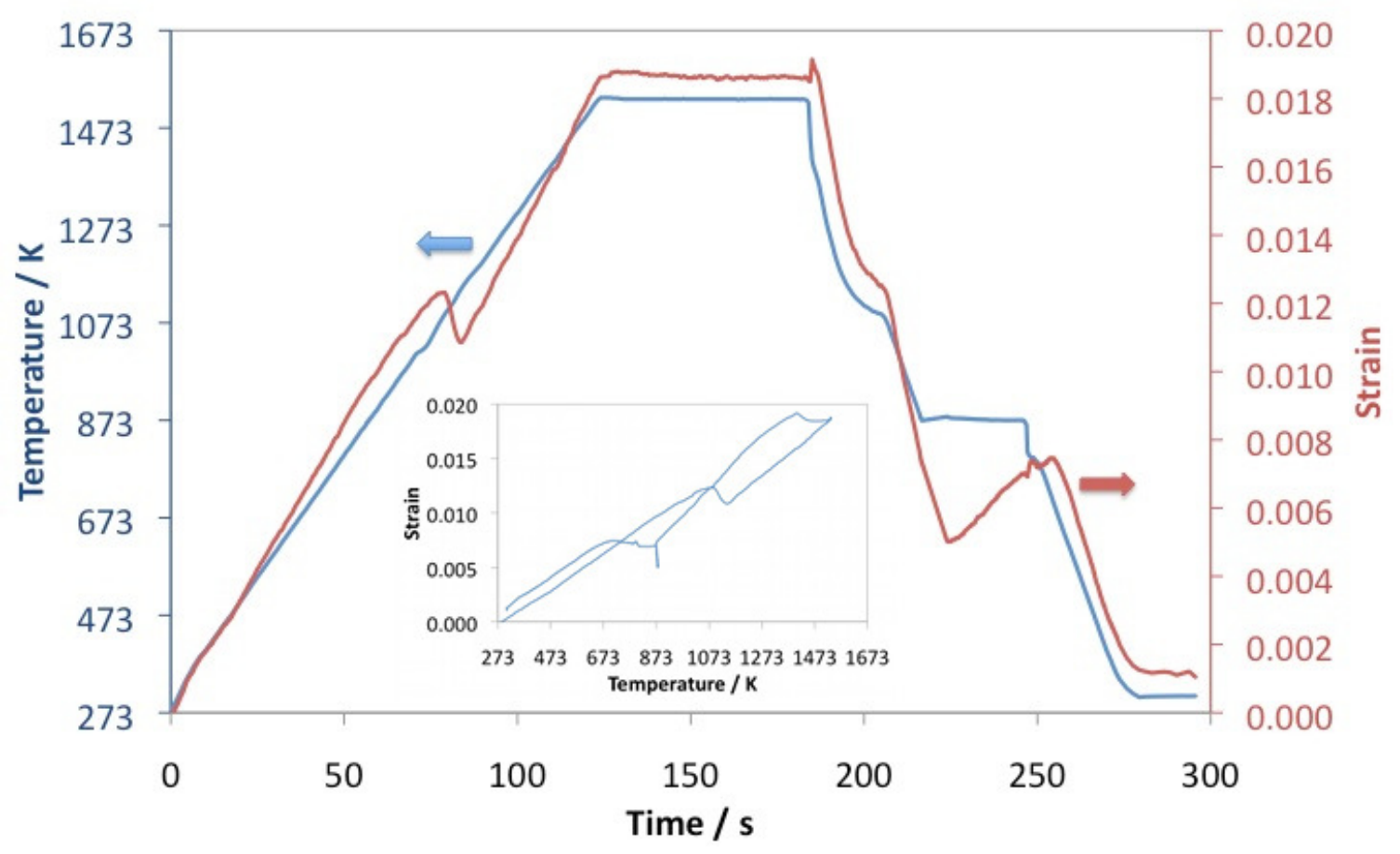

(a) Dilatometric curve.

Figure 5: Isothermal heat treatments at $873 \mathrm{~K}\left(600^{\circ} \mathrm{C}\right)$ for $30 \mathrm{~s}$. 


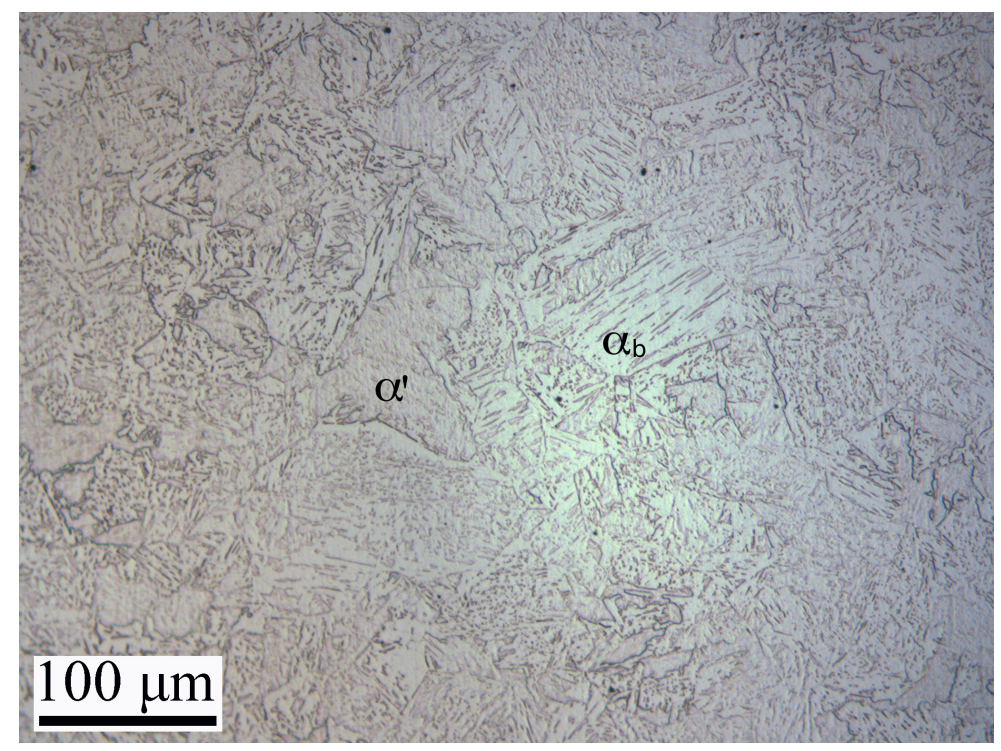

(b) Optical micrograph.

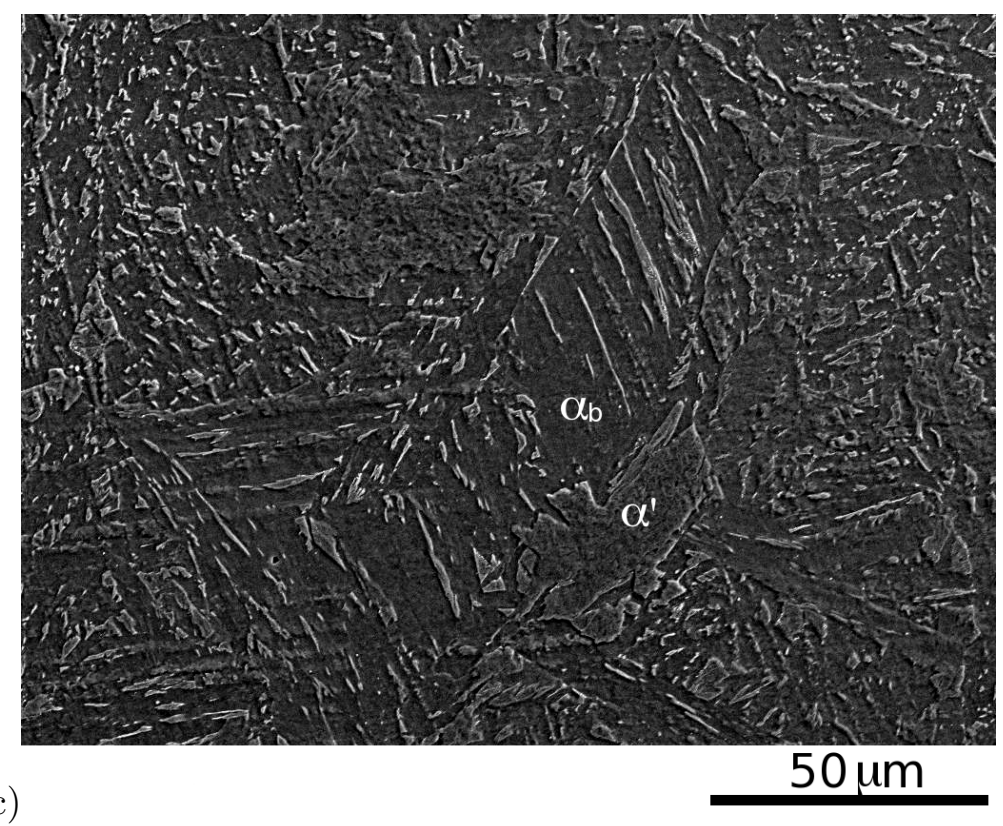

(c) Scanning electron micrograph.

Figure 5: Isothermal heat treatments at $873 \mathrm{~K}\left(600^{\circ} \mathrm{C}\right)$ for $30 \mathrm{~s}$. 


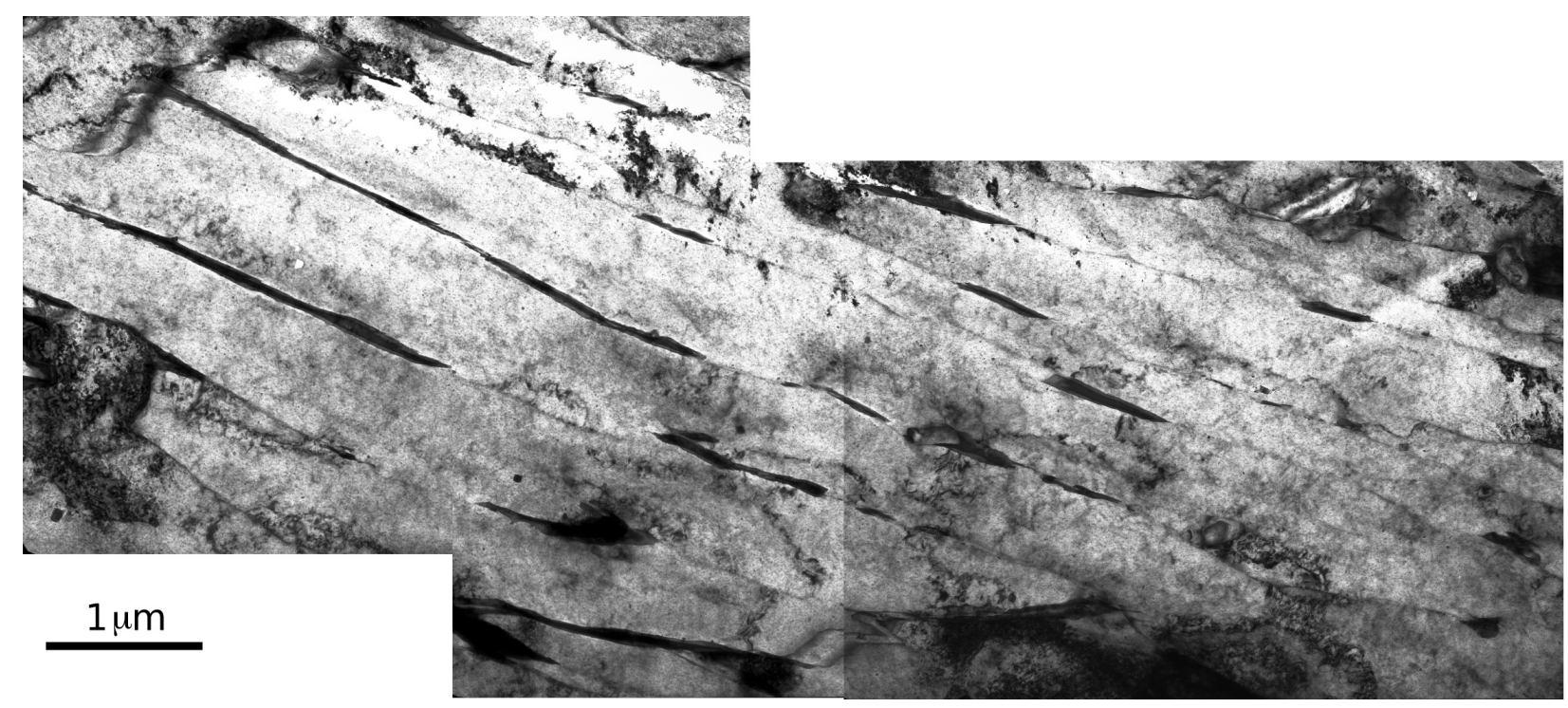

(a) Bright field image.

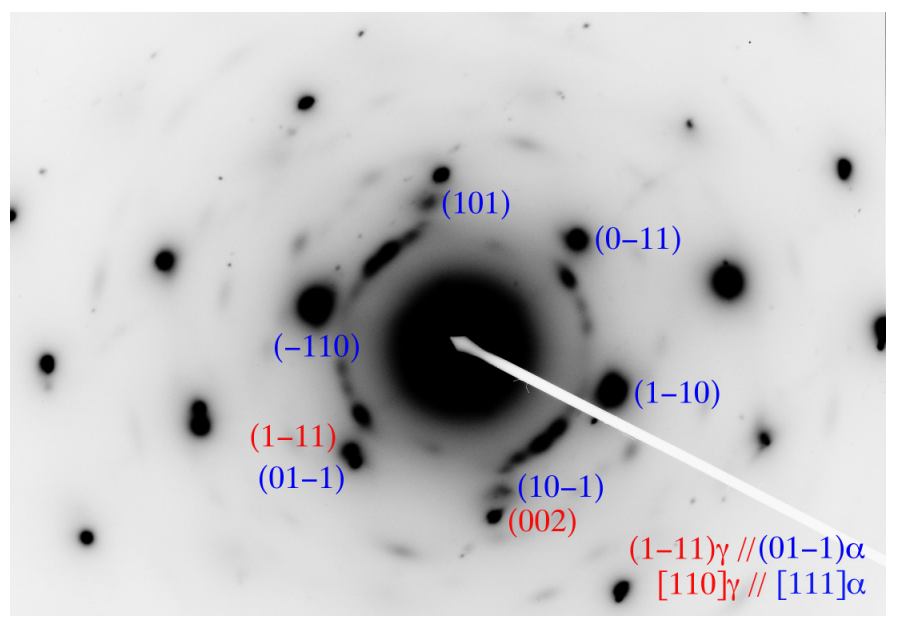

(b) Electron diffraction pattern.

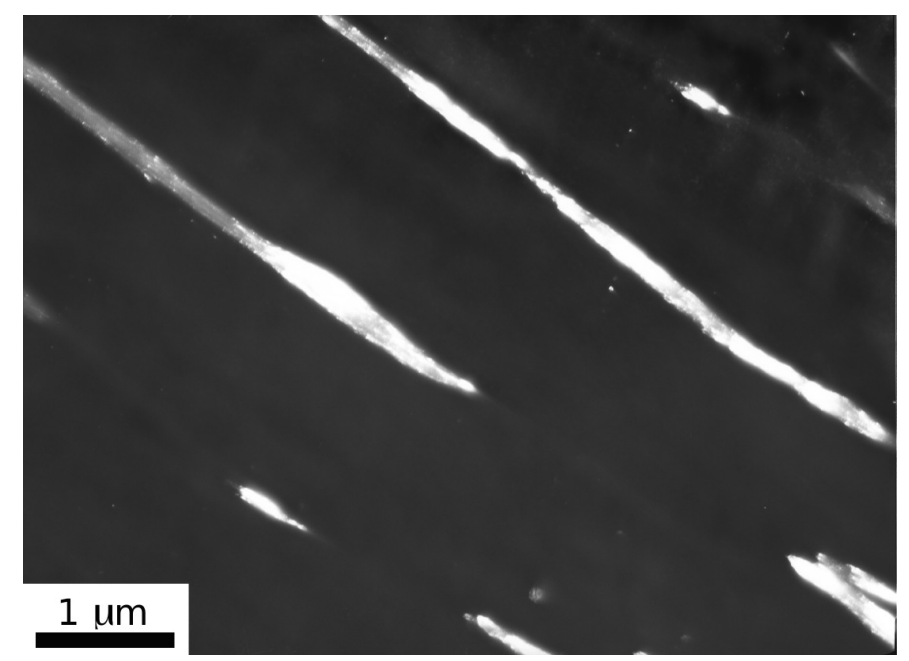

(c) Dark field image by selecting the diffraction from the austenite.

Figure 6: Transmission electron micrographs of the sample Isothermally held at $873 \mathrm{~K}\left(600^{\circ} \mathrm{C}\right)$ for $30 \mathrm{~s}$. 


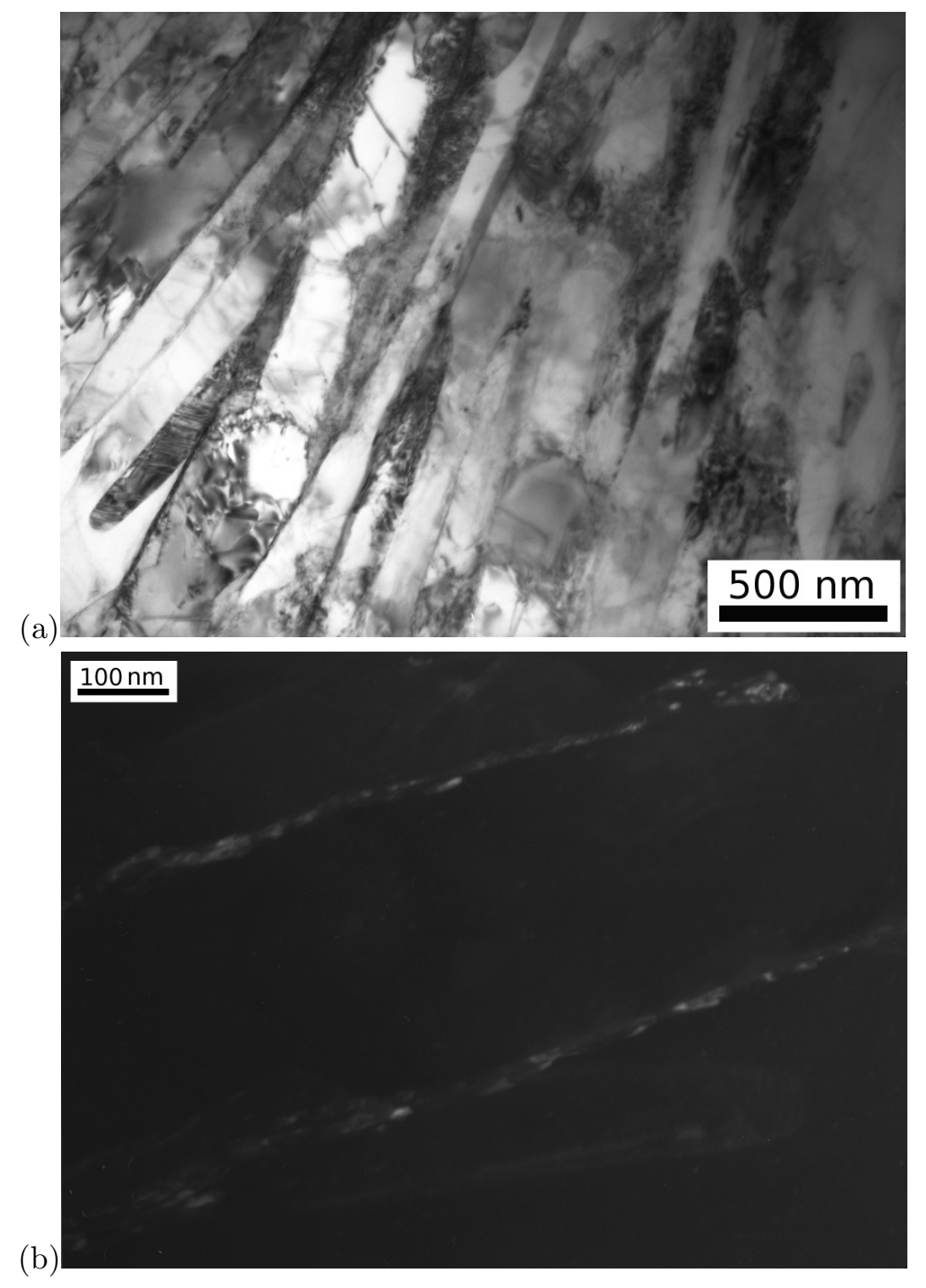

Figure 7: Transmission electron micrographs of the sample isothermally held at $873 \mathrm{~K}\left(600^{\circ} \mathrm{C}\right)$ for $1 \mathrm{~h}$ : (a) bright field image and (b) dark field image by selecting the diffraction from cementite. 


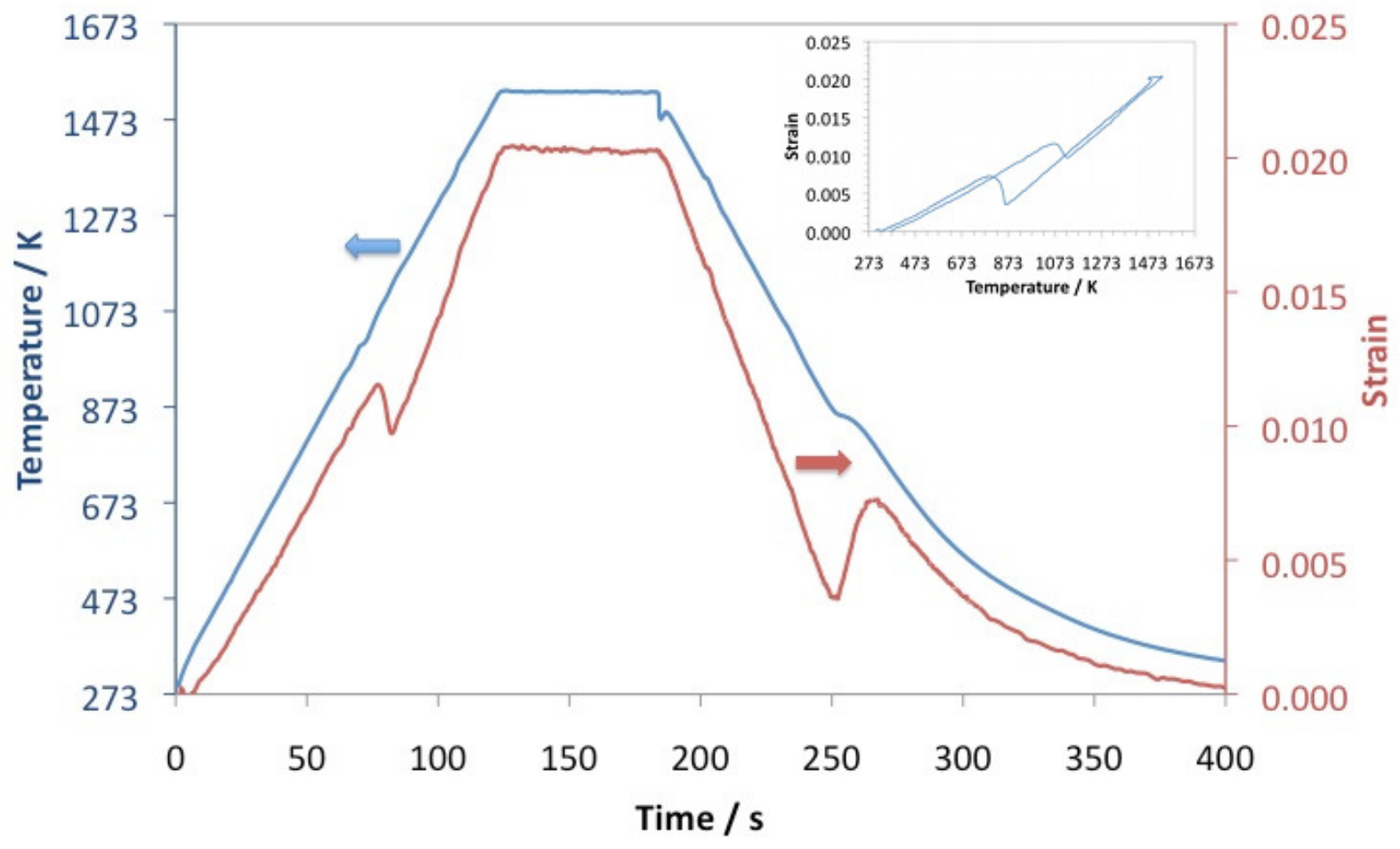

Figure 8: Dilatometry curve of the sample used to study the surface relief. 


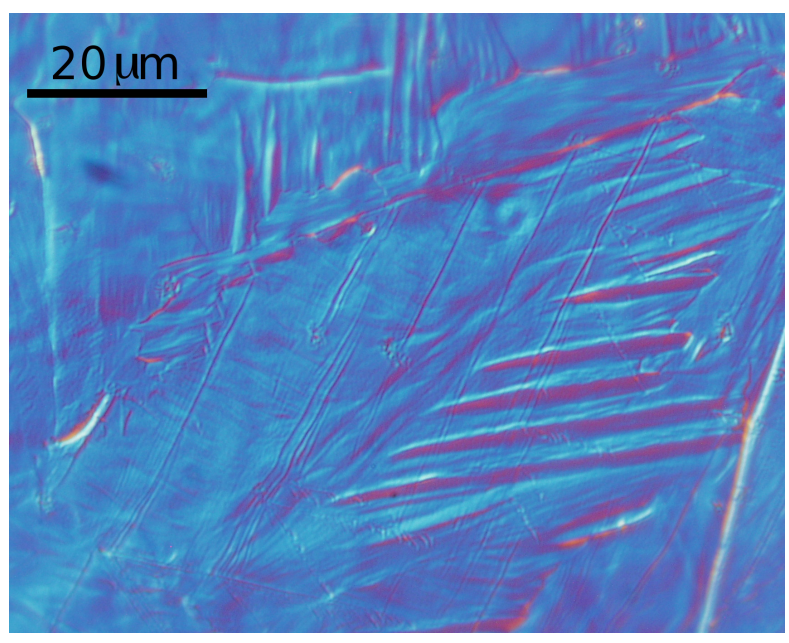

(a) The bainite plates under differential interference contrast using optical microscopy.

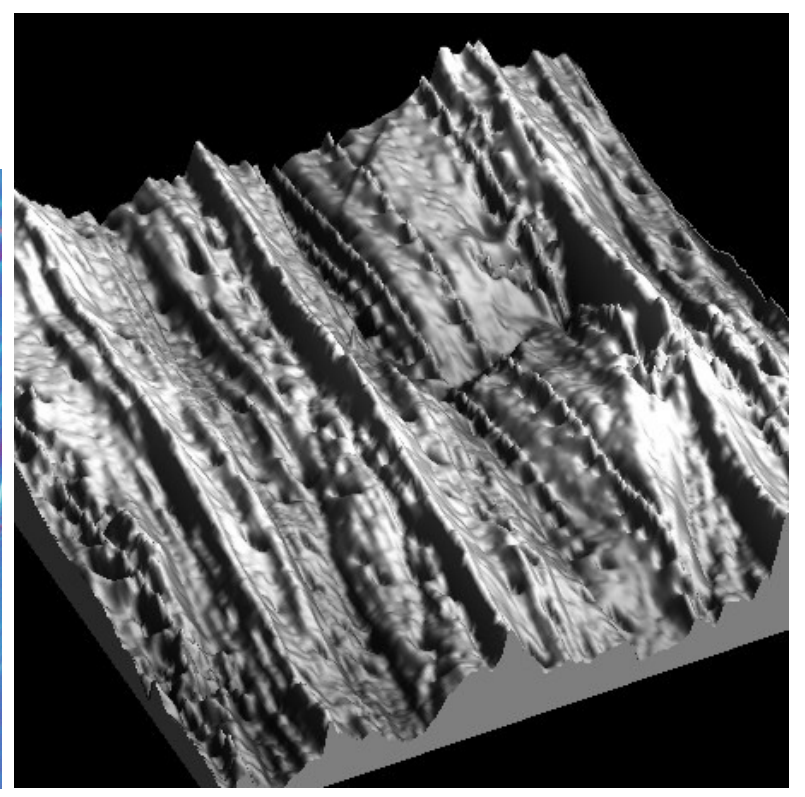

(b) Topography of the bainite plates in a surface area of $20 \times 20 \mu \mathrm{m}$ using atomic force microscopy, the maximum vertical height is $246 \mathrm{~nm}$.

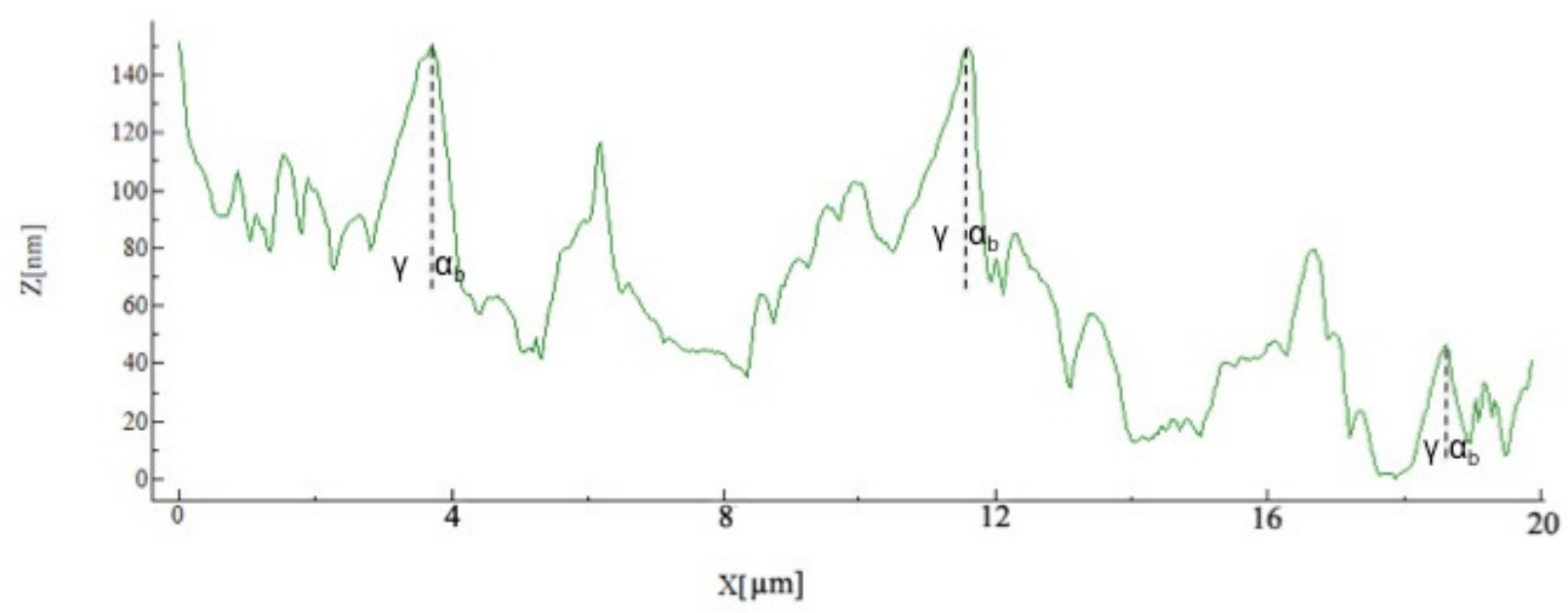

(c) A line scan across the bainite plates.

Figure 9: Surface relief of the bainite in the linepipe steel. 